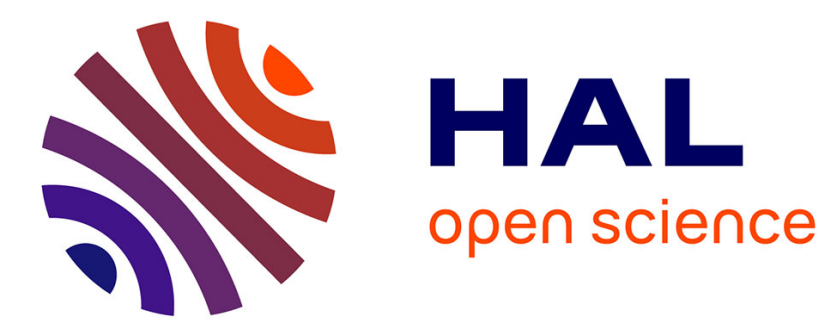

\title{
A metallurgical approach to individually assess the rheology of alpha and beta phases of Ti-6Al-4V in the two-phase domain
}

\author{
Michel Saby, Elisabeth Massoni, Nathalie Bozzolo
}

\section{- To cite this version:}

Michel Saby, Elisabeth Massoni, Nathalie Bozzolo. A metallurgical approach to individually assess the rheology of alpha and beta phases of Ti-6Al-4V in the two-phase domain. Materials Characterization, 2014, 89, pp.88-92. 10.1016/j.matchar.2014.01.001 . hal-00947591

\section{HAL Id: hal-00947591}

https://hal-mines-paristech.archives-ouvertes.fr/hal-00947591

Submitted on 8 Jun 2018

HAL is a multi-disciplinary open access archive for the deposit and dissemination of scientific research documents, whether they are published or not. The documents may come from teaching and research institutions in France or abroad, or from public or private research centers.
L'archive ouverte pluridisciplinaire HAL, est destinée au dépôt et à la diffusion de documents scientifiques de niveau recherche, publiés ou non, émanant des établissements d'enseignement et de recherche français ou étrangers, des laboratoires publics ou privés. 


\title{
A metallurgical approach to individually assess the rheology of alpha and beta phases of Ti-6Al-4V in the two-phase domain
}

\author{
Michel Saby ${ }^{\mathrm{a}}$, Elisabeth Massoni ${ }^{\mathrm{a}}$, Nathalie Bozzolo ${ }^{\mathrm{a}}$ \\ ${ }^{a}$ Mines ParisTech, CEMEF - Centre de Mise en Forme des Matériaux, CNRS UMR 7635 CS 10207 \\ 1 rue Claude Daunesse, 06904 Sophia Antipolis cedex, France
}

\begin{abstract}
An original hot torsion procedure is presented using Ti-6Al-4V in the two-phase domain. Kinetics of phase transformation are used to obtain stress-strain curves in off-equilibrium states. The individual influences of phase fraction and of temperature are quantitatively assessed in the two-phase domain. Between the two forging temperatures $1143 \mathrm{~K}\left(870^{\circ} \mathrm{C}\right)$ and $1228 \mathrm{~K}\left(955^{\circ} \mathrm{C}\right)$, a $95 \mathrm{MPa}$ stress difference is observed. The paper shows that this flow stress drop is mainly due to thermal activation, by $80 \mathrm{MPa}$, while $15 \mathrm{MPa}$ is due to the change of phase fraction. The stresses in each phase are individually assessed and stress-strain curves for each phase are obtained within the two-phase domain.
\end{abstract}

Keywords: titanium alloys, phase transformation, high-temperature deformation, torsion test

\section{Introduction}

Due to their considerable resistance to hard solicitations, fatigue, corrosion, and to their low density, titanium alloys today remain major candidates for the production of aeronautic structural parts. Immense effort is devoted to the improvement of the hot forging process of such large-scale parts. Constitutive models, associated with numerical simulation, are powerful tools to optimize forging stages. Empirical and semi-empirical constitutive models, considering thermo-mechanical variables (effective strain $\bar{\varepsilon}$, strainrate $\dot{\bar{\varepsilon}}$, and temperature $T$ ) are widely used [1-4]. Over last decades, physically-based

Email address: michel.saby@mines-paristech.fr, +33493957415 (Michel Saby) 
models including internal-state-variables [5-7] and self-consistent models $[8,9]$ were developed, according to numerous studies regarding deformation mechanisms and metallurgical changes in the material. Among all, phase fraction emerges as a very influent parameter on flow stress, and the alloy's rheological behavior may be expressed using a rule of mixture (rom):

$$
\sigma(\bar{\varepsilon}, \dot{\bar{\varepsilon}}, T)=\operatorname{rom}\left[\sigma_{\alpha}(\bar{\varepsilon}, \dot{\bar{\varepsilon}}, T), \sigma_{\beta}(\bar{\varepsilon}, \dot{\bar{\varepsilon}}, T), f_{\alpha}(T)\right]
$$

where $\sigma$ is the flow stress of the alloy, $\sigma_{\alpha}$ and $\sigma_{\beta}$ the individual flow stresses of each phase, and $f_{\alpha}$ the volume phase fraction of alpha phase. In the two-phase domain, the temperature dependence of $\sigma$ is therefore driven by two complementary effects: (i) the change of phase fraction $f_{\alpha}(T)$ according to phase equilibrium thermodynamics, and (ii) the temperature dependence of $\sigma_{\alpha}(T)$ and $\sigma_{\beta}(T)$ due to thermal activation in each phase. This paper presents an experimental procedure to assess those two influences individually.

\section{Experimental setup for in- and off-equilibrium torsion testing}

Two-phase $\alpha+\beta$ titanium alloy Ti-6Al-4V was supplied by TIMET Savoie. Its chemical composition is given in Table 1. The $\alpha$ phase volume fraction at room temperature is $92 \%$ and the transus temperature $(\alpha+\beta \rightleftharpoons \beta)$ is $T_{\beta}=1268 \mathrm{~K}\left(995^{\circ} \mathrm{C}\right)$. Hot torsion tests are conducted at the temperatures $1143 \mathrm{~K}\left(870^{\circ} \mathrm{C}\right)$ and $1228 \mathrm{~K}\left(955^{\circ} \mathrm{C}\right)$, and at the strain-rate $\dot{\bar{\varepsilon}}=0.5 / \mathrm{s}$. These temperatures are in the range of classical forging temperatures, in the two-phase domain. Hot torsion was preferred as it enables large deformation to be reached. This experimental testing is well suited for rheology characterization, as it avoids the presence of friction during testing, unlike compression testing.

The specimens have a cylindrical effective zone (diameter $6 \mathrm{~mm}$, length $10 \mathrm{~mm}$ ). In a first series of tests, a classical in-equilibrium procedure was conducted. They were heated up using a lamp furnace and held at the desired temperature before deformation, as presented in Fig. 1(a). Protection against oxidation was provided using argon flow. Heating rate is $10 \mathrm{~K} / \mathrm{s}$ and holding time is $10 \mathrm{~min}$. For preliminary verification of the microstructure, one specimen was water-quenched after holding time (dashed line in Fig. 1(a)). Its microstructure is presented in Fig. 2(b). Dark alpha nodules, as well as 
dark alpha lamellae can be observed in a brighter beta matrix. During quenching, the beta phase has transformed into a lamellar $\alpha+\beta$ structure, while alpha nodules remained unchanged. The volume fraction of alpha phase before quenching can thus be obtained by measuring the volume fraction of alpha nodules on the quenched specimen at room temperature. The values are presented in Fig. 3 using full dots, as well as theoretical values of phase fraction, given by Eq. (2) [10]. The good agreement obtained between the measured values and the theoretical curve shows that thermodynamic equilibrium was indeed reached at the end of the holding time.

$$
f_{\alpha}(T)=0.92\left(1-e^{-0.0085\left(T_{\beta}-T\right)}\right)
$$

In a second series of tests, the so-called off-equilibrium torsion tests, holding time was suppressed, as presented in Fig. 1(b), in order to enable the deformation to start before thermodynamical equilibrium was reached, i.e. when the alloy presents a different phase fraction.

Alpha phase fraction was measured on the quenched specimen (see Fig. 2(a)) in the off-equilibrium condition. The values are plotted with white dots in Fig. 3. A difference of about $27 \%$ phase fraction was obtained between in- and off-equilibrium cases at the temperature $1228 \mathrm{~K}\left(955^{\circ} \mathrm{C}\right)$, and about $12 \%$ at the temperature $1143 \mathrm{~K}\left(870^{\circ} \mathrm{C}\right)$.

The total deformation duration for each torsion test is $1 s$. Kinetics of phase transformation are neglected on this duration and phase fractions are therefore considered as constant during the whole deformation. Stress-strain curves are obtained using Fields \& Backofen's analysis [11], and the three associated assumptions are discussed in the following: (i) The fully-plastic deformation of the specimen was verified by a visual inspection of post-mortem specimens, by the absence of any localization effect. (ii) The temperature was measured by thermocouples and the increase due to self-heating remained lower than 10 K. Isothermal conditions must be considered for Fields \& Backofen's analysis. (iii) The material is assumed to be macroscopically homogeneous and isotropic according to

\begin{tabular}{ccccccc}
\hline $\mathrm{Al}$ & $\mathrm{V}$ & $\mathrm{Fe}$ & $\mathrm{O}$ & $\mathrm{C}$ & $\mathrm{N}$ & $\mathrm{Ti}$ \\
\hline 6.16 & 3.98 & 0.15 & 0.19 & 0.015 & 0.007 & remainder \\
\hline
\end{tabular}

Table 1: Chemical composition of Ti-6Al-4V in weight percent 


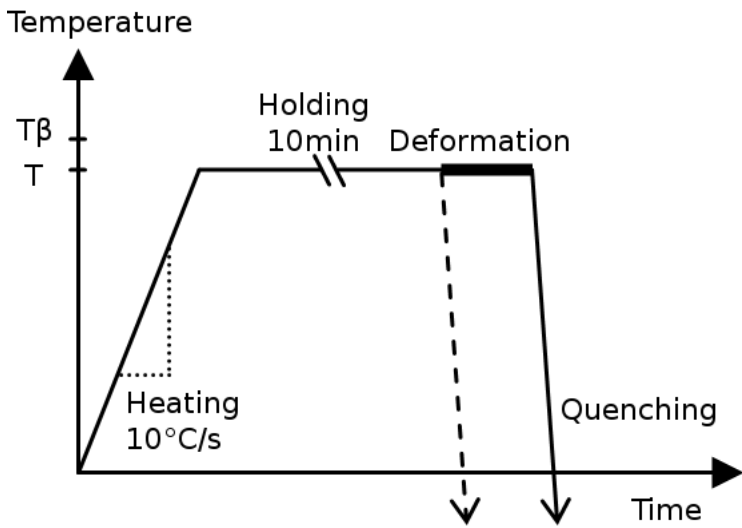

(a)

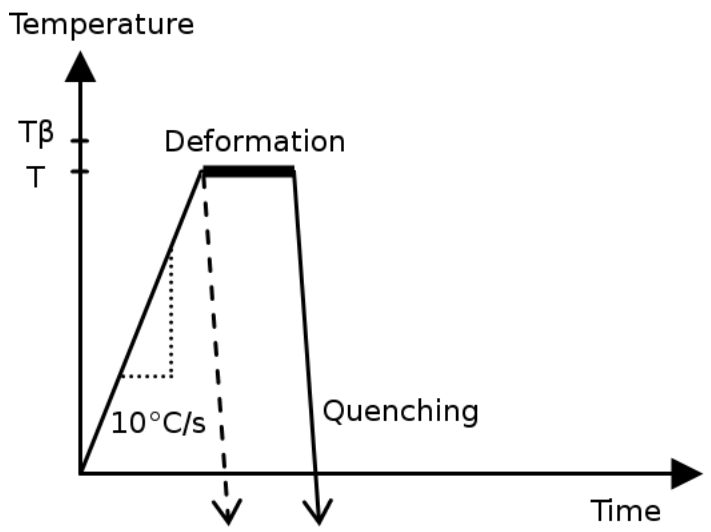

(b)

Figure 1: Temperature pattern for (a) in- and (b) off-equilibrium torsion test 
the rather equiaxed aspect of the alpha nodules on Figs. 2(b) and 2(a) and due to the absence of known texture effects in the sample. The final microstructure was observed in Fig. 2(c). It shows that the alpha nodules remain equiaxed after deformation (verification of (i) and (iii) conditions) and that phase fraction is unchanged (verification of the (ii) condition).

\section{Analysis of rheological data}

\subsection{Effects of temperature and phase fraction}

Stress-strain curves were obtained for the two temperatures $1228 \mathrm{~K}\left(955^{\circ} \mathrm{C}\right)$ and $1143 \mathrm{~K}\left(870^{\circ} \mathrm{C}\right)$, at equilibrium and off-equilibrium. Each condition was repeated three times to ensure reproducibility of the results. Experimental stress-strain curves for the four tested cases are presented in Fig. 4(a). The values of flow stress obtained at equilibrium (in full dots) at both temperatures are in good agreement with literature [7, 12]. At the temperature $1228 \mathrm{~K}\left(955^{\circ} \mathrm{C}\right)$ the flow stress values obtained in the off-equilibrium state $\left(f_{\alpha}=0.58\right)$ are higher than the values obtained at thermodynamical equilibrium $\left(f_{\alpha}=0.31\right)$. A change of $\Delta f_{\alpha}=0.27$ in phase fractions involves a relative difference in flow stress by about $20 \%$, which confirms that phase fraction has a significant influence on rheology [9]. At the temperature $1143 \mathrm{~K}\left(870^{\circ} \mathrm{C}\right)$, both values of flow stress are roughly comprised in the same range [160-170] MPa. In this case, the difference of phase fraction obtained using the experimental procedure at this temperature $\left(\Delta f_{\alpha}=0.12\right)$ was probably not sufficient to involve a significant effect on rheology.

Strain hardening and softening effects are rather moderate at such temperatures and strain rate. However, a slight difference in the strain hardening and softening behaviours can observed at the beginning of the stress-strain curves. It was shown $[5,13]$ that the presence of a peak in flow stress tends to vanish over transus temperature, i.e. in pure beta phase. In Fig. 4(a), the curves at highest values of $f_{\alpha}$ exhibit a sharper change of slope than the ones at the low $f_{\alpha}$. This results confirms that, in the two-phase domain, the presence of a peak can also be attributed to the behaviour of the alpha phase.

On Fig. 3, let us note that phase fractions measured at $1143 \mathrm{~K}\left(870^{\circ} \mathrm{C}\right)$ at equilibrium, and at $1228 \mathrm{~K}\left(955^{\circ} \mathrm{C}\right)$ off-equilibrium are very similar, respectively equal to 0.62 and 0.58. By assuming that both phase fractions are equal, it is possible to deduce the 


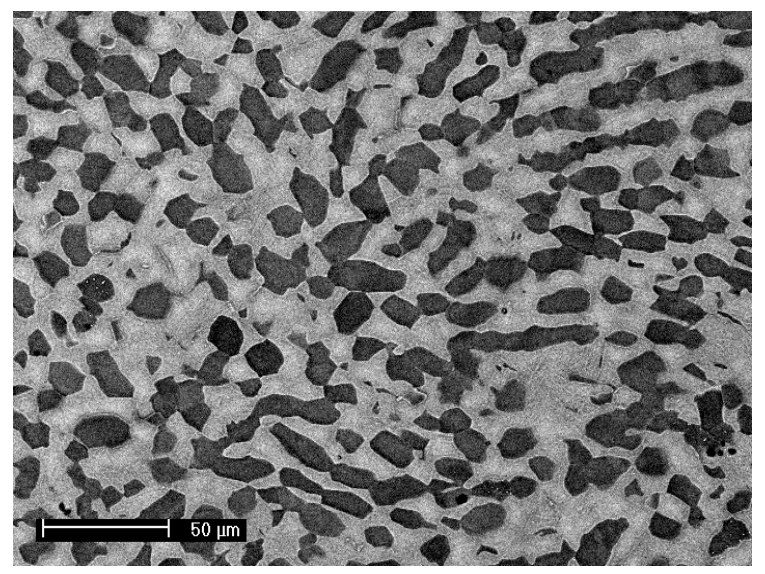

(a) Before holding

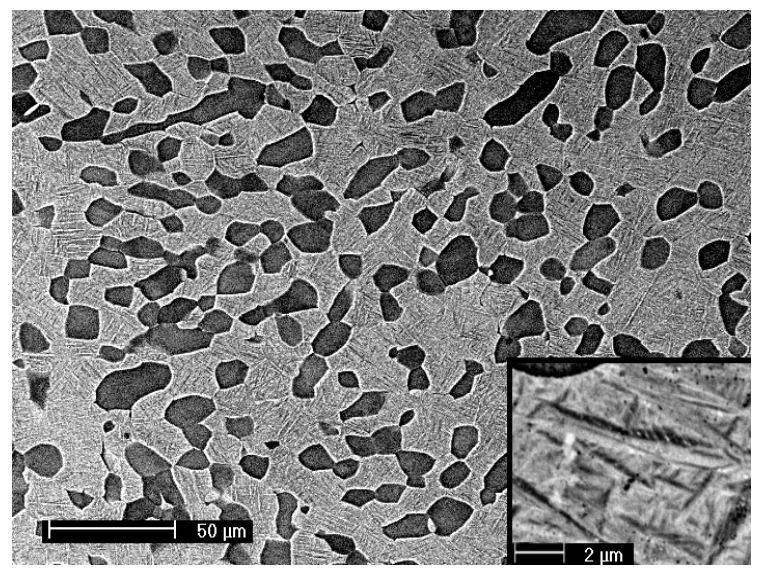

(b) After 10' holding at $1228 \mathrm{~K}\left(955^{\circ} \mathrm{C}\right)$

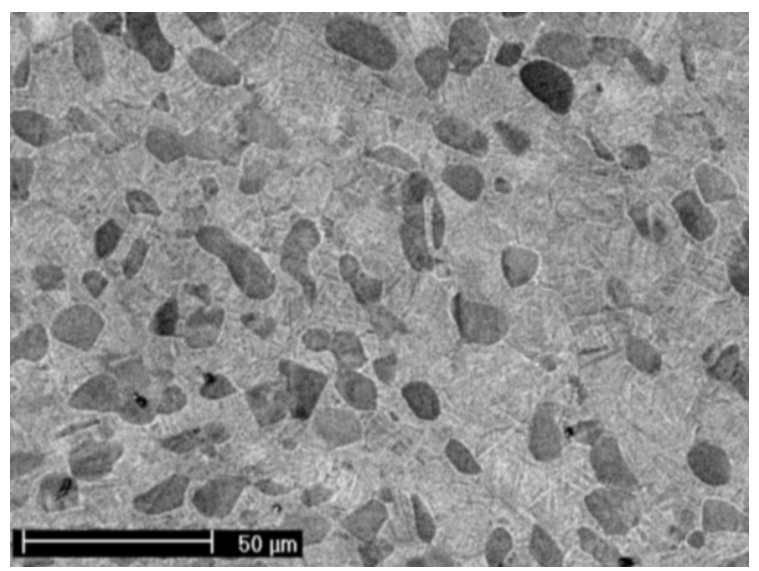

(c) After 10' holding and deformation

Figure 2: Microstructure obtained by quenching from the temperature $1228 \mathrm{~K}\left(955^{\circ} \mathrm{C}\right)$, at different instants, using back-scattered electron microscopy 6 


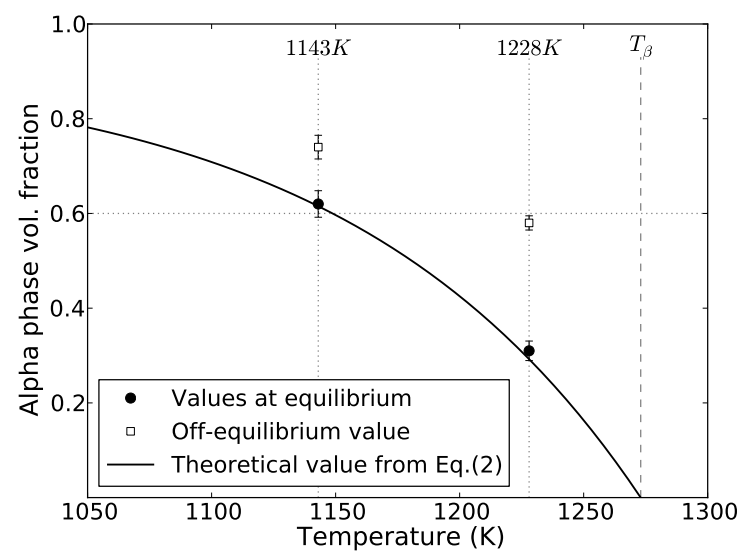

Figure 3: Measured primary alpha phase fractions vs. temperature

effect of a pure temperature increase, regardless of phase fraction. The flow stress of the alloy drops of about $80 \mathrm{MPa}$ due to temperature increase. The further natural phase transformation then continues reducing flow stress by $15 \mathrm{MPa}$, to reach the final value $65 \mathrm{MPa}$ at thermodynamical equilibrium.

To summarize, the total flow stress reduction of $95 \mathrm{MPa}$ due to heating alloy from $1143 \mathrm{~K}\left(870^{\circ} \mathrm{C}\right)$ to $1228 \mathrm{~K}\left(955^{\circ} \mathrm{C}\right)$ (at thermodynamic equilibrium) is due for $84 \%$ to pure thermal activation and for $16 \%$ to phase change.

\subsection{Stress-strain curves in each individual phase}

The overall flow stress of two-phase alloys can be expressed, in a first approximation, as a linear combination of individual flow stresses in each phase $[7,12,13]$. At a given temperature, the stress of the alloy in each case (equilibrium or off-equilibrium) is thus expressed as

$$
\begin{array}{lll}
\sigma(T)^{e q} & =\sigma_{\alpha}(T) f_{\alpha}^{e q} & +\sigma_{\beta}(T)\left[1-f_{\alpha}^{e q}\right] \\
\sigma(T)^{o f f e q} & =\sigma_{\alpha}(T) f_{\alpha}^{o f f} e q & +\sigma_{\beta}(T)\left[1-f_{\alpha}^{o f f e q}\right]
\end{array}
$$

with $\sigma_{\alpha}(T)$ and $\sigma_{\beta}(T)$ the stress in each phase, respectively. $\sigma(T)^{e q}$ and $\sigma(T)^{o f f e q}$ are the flow stress that were measured by torsion testing at equilibrium and off-equlibrium. At the temperature $1228 \mathrm{~K}\left(955^{\circ} \mathrm{C}\right)$, the resolution of this linear system provides values for individual stresses $\sigma_{\alpha}(1228 K)$ and $\sigma_{\beta}(1228 K)$. The values are plotted in Fig. 4(b) for the whole range of strain $\bar{\varepsilon}=[0-0.5]$. This figure verifies that the beta phase has a lower flow stress than alpha phase, which is in good agreement with literature $[9,13]$. It 


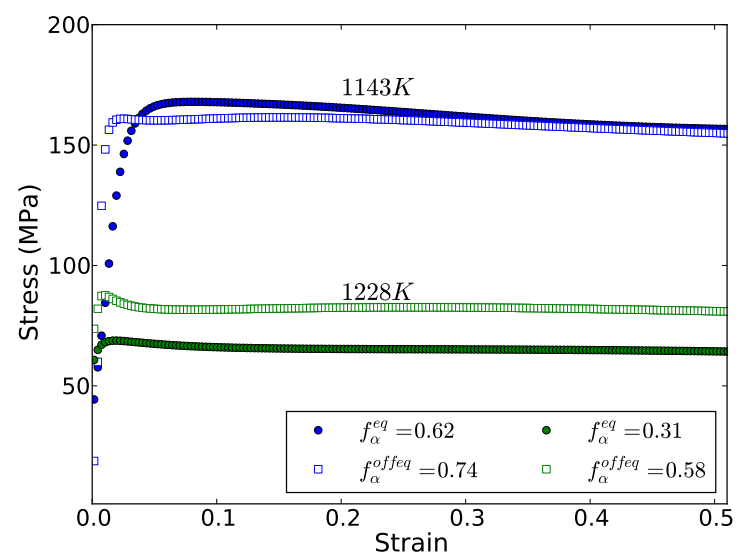

(a)

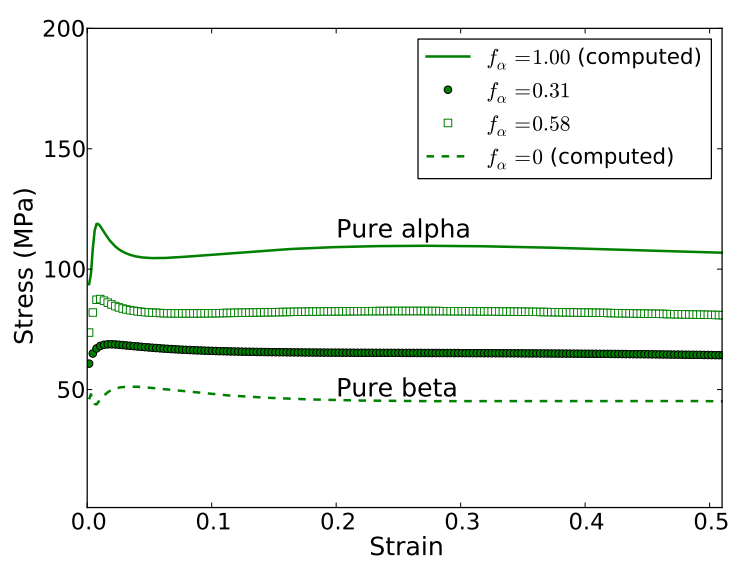

(b)

Figure 4: Stress-strain curves: (a) experimental data at various tested temperatures and phase fractions, and (b) experimental and computed data at $1228 \mathrm{~K}\left(955^{\circ} \mathrm{C}\right)$ for pure alpha and beta phases 
is additionnally found that the flow stress of pure beta phase has a value by about $60 \%$ lower than that of pure alpha phase at the temperature $1228 \mathrm{~K}\left(955^{\circ} \mathrm{C}\right)$. An evaluation of individual phase behaviours is also pointed out. It also verifies the presence of a sharp peak for the rheology of alpha phase, and a relatively smooth change of slope in the rheology of beta phase, as shown in $[5,13]$.

In order to better predict the behaviour of the two-phase material, the linear form used in Eq. (3) in a first approximation might obviously be improved. For example, the absence of significant difference between both flow stresses in- and off-equilibrium at the lower temperature $1143 \mathrm{~K}\left(870^{\circ} \mathrm{C}\right)$ cannot be predicted using Eq. (3). Additionnal rheological data might be obtained using the presented procedure of off-equilibrium torsion testing, at various temperatures, and by varying phase fraction values using different holding times. It is worth noticing that kinetics of phase dissolution are a key parameter to take into account in the experimental procedure. The difference of phase fraction is obtained by a competition between heating rate and $\alpha \rightarrow \beta$ phase transformation. A fast heating device is therefore recommended. Let us also note that initial microstructure (equixed or lamellar structure, grain size, etc.) has a non-negligible impact on phase transformation kinetics. A fully-equiaxed initial microstructure shall be prefered rather than a bi-modal or lamellar microstructure. Slower kinetics of phase transformation also help to better satisfy the assumption of constant phase fraction during deformation.

\section{Conclusions}

The original experimental procedure consists in performing hot torsion tests in offequilibrium conditions, by dealing with kinetics of phase transformation within the twophase domain of Ti-6Al-4V alloy. It is possible to obtain stress-strain curves for two different phase fractions, at constant temperature. It is also possible to obtain stressstrain curves at two different temperatures, for a constant phase fraction. Using such rheological data, it is therefore possible to individually assess rheological behaviours of each phase. The results for Ti-6Al-4V show that, between the two forging temperatures $1143 \mathrm{~K}\left(870^{\circ} \mathrm{C}\right)$ and $1228 \mathrm{~K}\left(955^{\circ} \mathrm{C}\right)$, the $95 \mathrm{MPa}$ stress difference that is obtained is mainly due to thermal activation, by $80 \mathrm{MPa}$, while $15 \mathrm{MPa}$ is due to the change of phase fractions. The obtained stress-strain curves were also used to provide an individual 
evaluation of both phase rheologies within the two-phase domain. It was shown that, for Ti-6Al-4V at $1228 \mathrm{~K}\left(955^{\circ} \mathrm{C}\right)$, the flow stress of beta phase is about $60 \%$ lower than that of alpha phase.

This metallurgical approach shows great potential to be adapted for further two-phase alloys.

\section{Acknowledgements}

This work was carried out in the frame of a project funded by an industrial consortium involving Airbus, TIMET Savoie, Forges de Bologne (Manoir Aerospace), Aubert 6 Duval (Eramet), and EADSIW.

[1] C.M. Sellars and W.J. McTegart. On the mechanism of hot deformation. Acta Metallurgica, 14(9):1136 - 1138, 1966.

[2] A. Hensel and T. Spittel. Kraft- und arbeitsbedarf bildsamer formgebungsverfahren, Leipzig, 1978.

[3] G. R. Johnson and W. H. Cook. A constitutive model and data for metals subjected to large strains, high strain rates and high temperatures. In Proceedings of the 7th International Symposium on Ballistics, volume 21, pages 541-547. The Hague, Netherlands: International Ballistics Committee, 1983.

[4] J. H. Sung, J. H. Kim, and R. H. Wagoner. A plastic constitutive equation incorporating strain, strain-rate, and temperature. International Journal of Plasticity, 26(12):1746-1771, 2010.

[5] P. Vo, M. Jahazi, S. Yue, and P. Bocher. Flow stress prediction during hot working of near-alpha titanium alloys. Materials Science and Engineering A, 447(1-2):99-110, 2007.

[6] X.G. Fan and H. Yang. Internal-state-variable based self-consistent constitutive modeling for hot working of two-phase titanium alloys coupling microstructure evolution. International Journal of Plasticity, 27(11):1833-1852, 2011.

[7] J. Luo, M. Li, X. Li, and Y. Shi. Constitutive model for high temperature deformation of titanium alloys using internal state variables. Mechanics of Materials, 42(2):157 - 165, 2010.

[8] S.L. Semiatin, F. Montheillet, G. Shen, and J.J. Jonas. Self-consistent modeling of the flow behavior of wrought alpha/beta titanium alloys under isothermal and nonisothermal hot-working conditions. Metallurgical and Materials Transactions A: Physical Metallurgy and Materials Science, 33(8):2719-2727, 2002.

[9] J.H. Kim, S.L. Semiatin, Y.H. Lee, and C.S. Lee. A self-consistent approach for modeling the flow behavior of the alpha and beta phases in Ti-6Al-4V. Metallurgical and Materials Transactions A: Physical Metallurgy and Materials Science, 42(7):1805-1814, 2011.

[10] R. Castro and L. Seraphin. Contribution à l'étude métallographique et structurale de l'alliage de titane TA6V. Mém. Scient. Rev. Métallurg. LXIII, 12:1025-1058, 1966.

[11] D.F. Fields and W.A. Backofen. Determination of strain-hardening characteristics by torsion testing. Proceedings of the 6th annual meeting of the society ASTM, 57:1259-72, 1957.

[12] Ji Kang Zhong, Matthew S. Dargusch, and Chris H.J. Davies. Modelling the high temperature deformation of Ti-6Al-4V. Materials Science Forum, 654-656:879-882, 2010.

[13] A. Colin, C. Desrayaud, M. Mineur, and F. Montheillet. A physically based flow rule for the simulation of Ti-6Al-4V forging in the $\alpha-\beta$ range. In Materials science forum, volume 539, pages 3661-3666. Trans Tech Publ, 2007. 